Published in Disability Studies Quarterly

Volume 35, Number 2, Spring 2015

Special Issue: Interventions in Disability Studies Quarterly

http://dsq-sds.org/

\title{
Embodiment, Environment, Disability Culture: Learning to Feel Ourselves in Space
} Petra Kuppers, petra@umich.edu

"All of us, disabled and nondisabled alike, will never truly understand disability experiences and identities unless we examine what we think we know. We all have a lot of relearning to do." Paul Longmore

In this short montage essay, I am sharing different student and teacher perspectives on a pedagogical exercise that allows us to relearn being in space. The exercise confounds conventional disability simulation exercises, imagining ourselves to be different than who we are, by substituting an experience of who we are already, perceived differently, with a more mindful attention.

In 2013, NYC-based choreographer Kathy Westwater came to visit with my disability culture undergraduate and graduate classes at the University of Michigan. We explored together how concepts of embodiment and environment can become active in our perception, and allow us new perspectives on disability culture, and on all the culture(s) we inhabit.

Before Westwater's visit, we had read some of her material on ecology and space management. The graduate class also read Mel Chen's chapter on Toxicity, in Animacies. In her essay, Westwater writes:

When it closed in 2001, Fresh Kills Landfill was the largest landfill in the world. The twenty-two hundred acre site took over 50 years to create and comprises four mounds - North, South, East, and West—-that together total 150 million tons of garbage. ..

In addition to the four landfill mounds, the site contains marshlands and waterways-the word "kills" is Dutch for stream; and it is described by landscape engineers and architects as a hybrid landscape, part natural and part man-made....

No longer active landfill and not yet parkland, our goal was to both record and create-to sketch into the landscape the current conditions that characterize the translation of this monument to consumption, from a site of trauma to a commons. ...

Since the 70s, I'd known about Fresh Kills, having seen the unforgettable, even for a child, photos of the backhoes, the mounds of detritus, and the scavenging seagulls. But it wasn't until I was sensing through my feet on top of all the tonnage-now covered in monolithic color and texture-that I understood when I threw something away, it went to a place like this. From that moment on my bodily processes of consuming, connected me not just 
conceptually, but materially and somatically in time and space to this site, thus concretizing the notion of the landfill being a prosthesis of my body.

$\cdots$

I created the Wandering and Belly scores to illuminate and document Fresh

Kills in its current liminal state. Wandering asks participants to "get lost" on a pathless landfill mound. While championing subjectivity, wandering becomes a means of trailbuilding, self-discovery, and spatial production. The physical sensations of negotiating the precarious landfill site correlate a contemporary landscape and body, made and remade, and thus contingent and unstable. These scores combined, extend wilderness and post-modern pedestrian practices, conceptually and practically, and in the midst of urban environmental trauma, speak to the ability of the individual to discern and adapt to a precarious environment. (Westwater, 2012)

In her visit, Kathy shared her practice with us, and gave us a Wandering score. While we didn't work on top of a landfill, but on a university campus, many of the themes in our readings stayed relevant: infrastructure, land shaping as prosthetic, and interdependency, human/non-human relations. Kathy's instructions were clear (and appropriate to this particular group, which did not include people with visual impairments): 20 minutes, silent walking, a group of four, keeping each other in sight. Group members may wander both near to and far from one another, so long as each and every member of the group is visible to one another at all times. We were asked to pay some attention to the topography we were moving about, but we were also invited to be open to what happened. Off we went.

\section{Student Writings}

In this section, I am sharing writings from the student blogs (with permission from the students), giving perspectives on the exercise.

Jenny Wang: Walking around with a group I wasn't just taking in the scenery around me, but I was also taking in the sounds. When no one in the group is talking, when there wasn't any music blasting in my ears, I had to make up for the "sound gap" with sounds from all around me. Our group went around the Diag area, so we were really close to the actual streets. I eavesdropped on conversations, on music, on the cars that drove by.

Niko Natsis: I have never simply just walked around and taken in the environment for the sake of enjoying it. I live in the mountains in Los Angeles by the beach and have never taken the time to stroll through either area. I noticed how quickly I normally walk. During this assignment, there was no end goal to reach or place to be. I have never walked at a pace that did not require any sort of extreme urgency to be somewhere.

Amy Milewski: I really enjoyed feeling the differences beneath my feet, how different the concrete feels from the grass, how some areas of grass were 
softer than others, how some areas had fallen acorns that changed how your foot related to the ground, and how my preferences for a particular "groundfeel" let me to wander more in some areas than others. Also, I enjoyed not being confined by needing to walk in a straight line. I am sometimes wobbly on my feet and may "misstep" sometimes, with this wandering exercise those "missteps" were simply the first steps in a new direction.

Alicia Wheeler: Walking around with my group was calming and energetic at the same time. In the almost 4 years that I have lived in Ann Arbor I have never taken the time to simply wander around the campus enjoying the nature, the artwork and the people walking by. I noticed so much more about this city than I think I ever have.

It was so interesting and shocking to hear people speak especially when they spoke near us loudly or with aggressive words while we were silent. It made that noise much more crass to hear than when I am speaking or on a mission to get somewhere.

Melissa Hershkovitz: What struck me most about wandering was the spaces in which it was considered normal to be wandering, i.e. on the grass or paths, and the spaces where it seemed less appropriate to wander, i.e. in flower beds. In the process of wandering I found myself receiving reprimanding looks, indicating that passing strangers disapproved of my presence in 'off limits' areas, and encouraging me to promptly exit those spaces. The idea of in bounds and out of bounds spaces is really interesting to me. The diag itself is interesting because it is a single space that has many different purposes, some couples flirt, some students study, people just hang out, some bring music and sing, others rarely notice it as they pass through, but all occupy the same space. ...

The activity with Kathy Westwater got me to deeply meditate on the spaces we have for disability in society. Her work in Fresh Kills landfill redefining spaces really stuck with me, and got me to think about the spaces that are 'in bounds' and 'out of bounds' for disabled individuals. These spaces seem to be a social convention that is only recently being confronted and altered. [In the following, Melissa refers to an earlier Skype guest speaker in our undergraduate class, Yvonne Schmidt from Switzerland, who had shared with us insights about the working processes Theatre HORA, a company of people deemed to have cognitive differences.]

The Swiss theater space is one that previous was 'out of bounds' for disabled individuals, however Theater HORA's work is akin to Kathy Westwater's spatial production in the way that Theater HORA has opened opportunities for cognitively disabled people to step into the previously out of bounds space of professional theater. The work of Theater HORA brings Swiss, and the international community, to question the previously held presumptions of theater, and reevaluate the theatrical space. 
Cari Carson: Perhaps the distinction is less between ability and disability than between appreciating and not appreciating. The characteristics of our bodies and minds could result in appreciation or not. Simulating a different ability-ness may heighten the appreciation; complacency with our own different abilities may lessen it.

But I wasn't thinking of any of this while wandering. When wandering, I just was. With ability and disability blurred, independence and dependence on other group members breathing life and accountability and creativity into my wandering, there was a playfulness and a joy and I-don't-have-more-nounsthat-mean-what-I-want-to-say-except worship.

Hillary Cleckler: I feel that I came to understand people in my class in different ways after this exercise. It was interesting to note who stayed at the front of the group and who stayed in the back. I also felt that we became comfortable with each other by staying near each other for twenty minutes. We didn't need to talk to become comfortable. I never realized the power that silence can have.

\section{Teacher Reflection}

In one of my Wanderings with my student group, I am trying to tune into the relationship between land, body, and prosthesis. Topographically, there are cuts and leverings that I had never noticed before. What is beneath the gentle rise of the land around the central plaza of our diag? Where did the land go, excavated for these deep buildings, their footprint sunk down into the ground? I think of the hills and contours of the land surrounding us, and become aware of elevations in ways I wasn't before.

The sediment of built environments presses into my attention, and while I am all sensate wanderer, I am also historian, wonderer, questing to find narratives in the spaces I traverse. I find the plaque that tells of the Native American land gift to the university, enabling the Detroit college to acquire the Ann Arbor land.

I find the green house that glows so comfortable when I leave from the library late at night. I lean on stone and peer through the windows - and one of my partners is standing just on the edge of my sight but peeking in through another pane. One partner hovers about 20 feet back, connected but in her singular circle. The last partner orbits in and out of this quadrangulation.

This exercise is calming, grounding, connecting. The imagery of the belly, digestion, settling and upsets make somatic sense to me: transforming space into place, I contour myself to this land, and to the spatial preferences of my partners.

The second time I wander, with my graduate group, my attention is drawn to a different thematic complex. What is the connection between these somatic exercises and a disability cultural perspective?

Here we are, a heterogeneous/homogenous group, statistically stratified in certain ways. We know from earlier work in this class that we are predominantly white, middle-class, US-located, English-first-language, and non-disabled. But in 
reality, in the attention to specificity, this sense of sameness quickly vanishes: in each group of four or five, on the different days we run this Wandering Score, difference quickly asserted itself, not statistically, but phenomenologically. Our actual numbers never changed, but the attention to small moments of difference grew. Among us are Native Americans, people from different Asian countries, AsianAmericans, African-Americans, Australians, Germans, Jewish people, Christian people, disabled people, people of different ages and classes. I experience the difference between statistical median and lived reality of minoritarian status, as I wheel very slowly, as I know that my fellow group members are scrutinizing me, tuning into me, as much as I tune into them.

My different form of locomotion is very clearly magnified, as the wheelchair is so visible. But we are all tuning into other mobility differentiations, too: pronounced or slight limps, age differences and their effects on embodiment, sports injuries. Equally experiential are other cultural ways of being in space, of being comfortable to step onto the grass, of getting one's shoes potentially muddy, of transgressing boundaries, of leading or being led, of the effects of university hierarchies, of the mysteries of being other.

This somatic score allows me time to be both at peace with myself, and to understand my contested prosthetic relation to time and space. It also allows me a new perspective on different scales and order of difference between me and the others I share space with. The space shifts into view in a new way: soft and hard, muddy or solid, old or new, excavated holes and curious mountings. The land rises to our wandering bodies.

\section{A Suggested Exercise:}

Engage in a wandering exercise yourself. Invent your own: come up with an exercise that combines space traversing with group consciousness. Make sure that there is a divided attention going on, somehow. Then commit to it, do it. After the exercise is over, engage in a sharing circle. What happened? What did you feel, what did you think, what came to your consciousness? How did you see others, how did you experience yourself, how did you experience the land? There is no right or wrong way of doing this exercise, and there is no particular 'topic area' that needs to be covered: this is an exercise of mindfulness, of being open to influence.

If you use student blogs or course software, invite written reflections. How do they differ from the immediate impressions shared just post-wandering? How do writing styles differ, how do we present ourselves in verbal and written media?

\section{Note:}

This mini-essay was originally conceived as a section of Studying Disability Arts and Culture: An Introduction (Petra Kuppers, 2014, Palgrave), but it got a bit too long, so now it is this stand-alone meditation. The book contains many more embodiment exercises.

\section{Bibliography:}


Chen, Mel Y. 2012. Animacies: Biopolitics, Racial Mattering, and Queer Affect. Durham: Duke University Press.

Kuppers, Petra. 2014. Studying Disability Arts and Culture: An Introduction. Harmondsworth: Palgrave.

Westwater, Kathy. 2012. Pageantry, Prosthetics and Performative Acts of Walking at Fresh Kills." Society for Dance History Scholars Conference, unpublished paper. 